
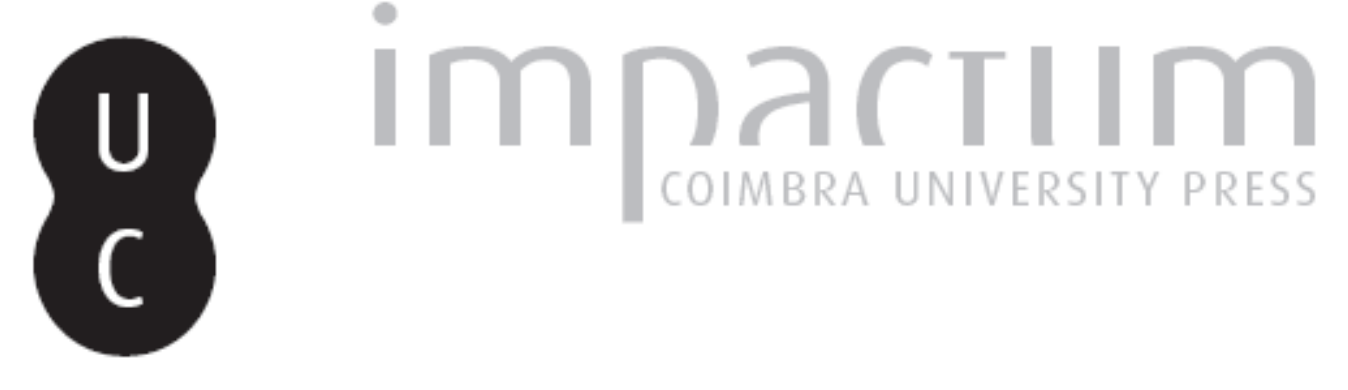

\title{
O Liberalismo
}

\section{Autor(es): $\quad$ Rodrigues, José Honório}

Publicado por: Imprensa da Universidade de Coimbra

URL persistente:

URl:http://hdl.handle.net/10316.2/43969

DOI:

DOl:https://doi.org/10.14195/2183-8925_1_1

Accessed : $\quad$ 26-Apr-2023 14:47:55

A navegação consulta e descarregamento dos títulos inseridos nas Bibliotecas Digitais UC Digitalis, UC Pombalina e UC Impactum, pressupõem a aceitação plena e sem reservas dos Termos e Condições de Uso destas Bibliotecas Digitais, disponíveis em https://digitalis.uc.pt/pt-pt/termos.

Conforme exposto nos referidos Termos e Condições de Uso, o descarregamento de títulos de acesso restrito requer uma licença válida de autorização devendo o utilizador aceder ao(s) documento(s) a partir de um endereço de IP da instituição detentora da supramencionada licença.

Ao utilizador é apenas permitido o descarregamento para uso pessoal, pelo que o emprego do(s) título(s) descarregado(s) para outro fim, designadamente comercial, carece de autorização do respetivo autor ou editor da obra.

Na medida em que todas as obras da UC Digitalis se encontram protegidas pelo Código do Direito de Autor e Direitos Conexos e demais legislação aplicável, toda a cópia, parcial ou total, deste documento, nos casos em que é legalmente admitida, deverá conter ou fazer-se acompanhar por este aviso.

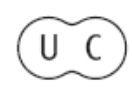




$$
\text { INSTITUTO DE HISTÓRIA E TEORIA DAS IDEIAS }
$$

\title{
REVISTA DE HISTÓRIA $D A S$ IDEIAS
}

\author{
VOL. I
}

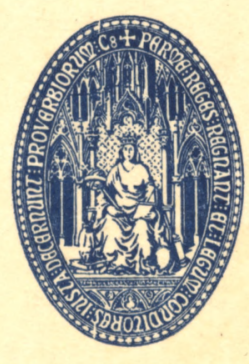

UNIVERSIDADE DE COIMBRA 


\section{O L I B ER A LISMO $\left(^{*}\right)$}

O liberalismo vitorioso em Portugal em 1820 era de tonalidade conservadora. Isso significa que era moderado no pensamento político, que não queria destruir a monarquia, nem queria implantar o republicanismo. Estava associado ao liberalismo económico, que era a armadilha com que se aprisionavam nações ao imperalismo sobretudo britânico. Um liberalismo que aceita manter a dependência brasileira, que não via a subjugação aos ingleses, que impunha apenas condiçð̃es limitativas à autoridade real, não é verdadeiramente senão moderado e contido. O vintismo português (revolução de 1820) assistiu a uma luta entre liberais, conservadores e absolutistas, tanto no campo doutrinário, quanto na aç̧ão combativa. $\mathrm{Na}$ própria revolução já estavam os germes da contra-revolução, que logo depois em 1823 tomará uma feição doutrinária e tradicionalista e vencerá e perderá. Aos liberais opunham-se menos os conservadores, que os contra-revolucionários, pois não havia um liberalismo radical, republicano, bem organizado, o que facilitava a compreensão entre liberais e conservadores. Os contra-revolucionários queriam a volta ao absolutismo, sem promessas liberais.

O liberalismo português não foi influente no Brasil, na medida em que ele se opôs a tudo, absolutamente tudo, a que aspiravam os liberais brasileiros. No fundo, o liberalismo português era conservador, visando apenas reformar o que fosse possível reformar, respeitando as estruturas tradicionais. Ele nunca foi radical, democrático, e o máximo a que chegou, um pouco depois da independência brasileira, em 1834, com D. Pedro IV (I no Brasil) foi atender àquilo que Alexandre Herculano chamou de positivismo liberal, e que con-

(*) Parte do capítulo $1 .^{\circ}$, «Ideologias, Facções e Vocabulário Político», do livro Independência: Revolução e Contra-Revolução, vol. $1 .^{\circ}$, Evolução Política, a sair em 1976. 
sistia num conjunto de reformas que freiassem o poder da Igreja e da nobreza, para benefício da burguesia e da pequena burguesia. $O$ pensamento pequeno-burguês do liberalismo português se revelava na sua ogeriza às ideias de liberdades para todos, e da igualdade política e jurídica de todos.

O liberalismo português era reformista da organização do Estado, dividindo a soberania entre o Rei e Povo, este reduzido na sua capacidade jurídica, pois havia escravos e os que não votavam porque não atingiam a renda mínima. Ou não eram cidadãos ou o eram passivamente; era reformista economicamente, aceitando a liberdade comercial e de portos, para Portugal, e não para o Brasil (1).

Deste modo o liberalismo português foi sempre conservador, ainda que dentro dele correntes pessoais se hostilizassem.

O liberalismo português acabou com o legitimismo real, com a ideia da origem divina da soberania real, com a indivisibilidade da soberania, e tudo isto não foi pouco serviço à evolução histórica. Se eles atacavam o fanatismo religioso, a Inquisição, defendiam a tolerância, e as liberdades públicas.

Se os liberais são utópicos, os conservadores são pragmáticos, e os contra-revolucionários são absolutistas arbitrários e despóticos.

O liberalismo estimulou as possibilidades da criatividade humana, que o conservadorismo limitava e os tradicionalistas ou contra revolucionários liquidavam. A concepção liberal que influiu em Portugal ou no Brasil entendia, via Rousseau, que existiam uma liberdade e igualdade naturais que era preciso preservar tanto quanto possível. Daí a necessidade do contrato social, que seria a garantia de tais direitos e consequentemente da ordem social. Montesquieu primeiro e depois Rousseau são as principais influências modeladoras do pensamento revolucionário liberal, sendo o segundo traduzido para o português desde $1821\left({ }^{2}\right)$. Rousseau, sobretudo, apresentava um modelo político negando que o statu quo conferisse legitimidade às instituiçðes.

A sociedade como a história, pensavam os liberais, não está nunca constituída, mas constituindo-se. Nunca vivemos num presente, mas sempre num gerúndio. Havia, assim, no liberalismo uma

(1) Vide J. Barradas de Carvalho, As ideias politicas e sociais de Alexandre Herculano, Lisboa, 1949.

(2) O Contrato Social ou principios do direito politico, Lisboa, 1821. 
busca de redenção do homem e da sociedade, uma utopia que só se conseguia vencendo a realidade tradicional, construindo um produto histórico novo.

Para isso a primeira missão era destruir a monarquia absoluta, o absolutismo e os mitos que o acompanhavam, como a crença na origem divina dos reis e na legitimidade da continuidade real. Para o liberalismo moderado - que foi o português e o brasileiro - o rei é apenas um elemento do Estado, com uma função determinada e relevante. Para limitar a sua autoridade e estabelecer legalmente a sua função, era necessário uma constituição escrita, que definisse também toda a organização estatal, os poderes e os direitos e deveres do rei e do povo. Sem isso, tudo seria uma usurpação, e o liberalismo contrapunha ao estado real, pessoal, o estado legal, constitucional. Desde então a revolução é uma redenção, é uma benção, porque restabelece os direitos de todos numa igualdade legal constituída, que pode renovar-se constituindo-se de novo.

O liberalismo estabeleceu, assim, um optimismo revolucionário, que acreditava sobretudo no progresso, uma criação iluminista (1), e nos saltos e empurrões históricos, e não numa evolução orgânica, lenta e natural.

O liberalismo criou um vocabulário político próprio, do qual trataremos adiante. Mas a essência da sua ideologia política é a teoria da representatividade, pela qual o povo faz representar os seus interesses, e com a qual se destrói o absolutismo. Qualquer que tenha sido a crítica aos sistemas eleitorais que regulavam essa representatividade, quaisquer limitações que eles tenham trazido à representatividade, o certo é que eles exprimiam mais a vontade geral, que a permitida pelo absolutismo, nas suas cortes. No absolutismo podia predominar, segundo a pessoa do Rei, a tirania ou o despotismo.

O liberalismo do começo do século dezanove não trazia a democracia, nem em Portugal, nem no Brasil, porque o liberalismo, como já dissemos, conviveu com a escravidão e limitou as concessões liberais a certos grupos sociais, e não a todos. Uns eram mais iguais que outros, e por isso houve sempre discriminação política, reflexo da discriminação social.

(1) Com o sentido de evolução da humanidade, de civilização, é palavra de 1757 na França; vide PAUl RoBert, Dictionnaire Alphabetique Analogique de la Langue Française, Paris, 1972; no sentido político de progressista é de 1845, segundo Robert. 
Não foi necessário chegar-se mais tarde à democracia liberal - que é uma forma evoluída de liberalismo político - para se sustentar a soberania do povo. Esta é outra ideia fundamental do liberalismo, e veremos como os nossos liberais a sustentaram, e como os conservadores conciliam a soberania dividida entre o Rei e o Povo.

Outro princípio surgido de imediato que dividiu liberais e conservadores foi a fórmula federativa ou centralizadora, e que se manifestou já na Assembleia Constituinte de 1823 (1).

Com toda essa doutrinação os liberais justificavam a legitimidade da Revolução para atingir esses fins, destruindo o estado autoritário, criando outro regido por leis, especialmente pela Constituição. O liberalismo negava a origem divina dos reis e com isso destruía o fundamento da autoridade real. Finalmente eles criaram, no seu desenvolvimento, o mito do herói da liberdade, que luta e combate pela vitória dos ideais liberais. Daí, mais tarde, a obra de Carlyle sobre o herói na história.

Essas as ideias gerais que eram importadas da Europa, produtora mundial de ideologias, e adoptadas no Brasil com ou sem consideração às circunstâncias históricas e locais.

Todas as ideologias são sempre internacionais, mesmo no país de origem. Todas as ideias políticas clássicas nascidas na Grécia, as religiões, as concepções culturais, foram universais quando tiveram força para o serem. A adaptação ou o sincretismo resultou da capacidade acolhedora e assimiladora dos povos recipiendários.

Basta ler a literatura panfletária política portuguesa e a réplica brasileira para ver que espécie de liberalismo era então divulgado. $\mathrm{O}$ chefe do liberalismo português, Manuel Fernandes Thomaz, é um desembargador com uma ideologia pequeno-burguesa que dominou o liberalismo português de 1820. As reformas deviam-se fazer nas pessoas e nas coisas e as ideias com que foi criado revelam um moralismo pequeno-burguês. Para ele era necessário ser português somente, porque houve tempo em que tudo foi inglês, e aquele em que tudo foi francês, e sucedeu outro em que tudo era espanhol, e agora ia tomando seus laivos de napolitano (2).

(1) José Honório Rodrigues, A Assembléia Constituinte de 1823, Vozes, Petropolis, 1974.

(2) Carta do Compadre de Belém ao Redator do Astro da Lusitania dada à luz pelo compadre de Lisboa, Lisboa, 1820. A atribuição foi feita por A. Do VALLE. 
O que se defendia era a elaboração da constituição, ainda não feita, e sua aceitação pelo Rei. "Tenho ouvido em toda a parte, que nós havemos de ter uma constituição, e uma monarquia constitucional, porque é necessário e indispensável em nossa situação política, e porque ninguém tem direito nem autoridade para o impedir. O que me parece sem dúvida é que toda a Nação está deliberada a acabar antes, e a sepultar-se debaixo de suas ruínas, do que deixar incompleta esta grande obra que tem começado» (1).

Propunha o chefe liberal uma grande difusão das ideias liberais por meio de catecismos para os homens do campo, e «dramas fartos de ideias liberais» para os da cidade. Defensor de que viva a nação sujeita ao monarca, e que sua pessoa seja sagrada, Manuel Fernandes Thomaz condenava os heróis que assassinam ou detestam reis e defendem como o melhor dos governos o governo republicano.

Atacava a ignorância dos princípios económicos e defendia os bons princípios liberais económicos. O liberalismo português mais ainda que o brasileiro no começo se associou aos comerciantes. As máximas do liberalismo económico - e não político - eram próprias dos comerciantes e deviam ser mais próprias ainda dos comerciantes portugueses que dos brasileiros, pois estes estariam sujeitos aos primeiros.

Defendia a liberdade de imprensa, uma necessidade nos regimes representativos, um contra-senso nos governos absolutos e autoritários. Portugal acordara gritando reforma, reforma.

Na Carta Segunda do Compadre de Belém (2), Manuel Fernandes Thomaz escrevia que uos portugueses são homens para tudo: o que lhes faltava era um Governo, que os pudesse fazer felizes, respeitando sua liberdade, porque eles sem dúvida são capazes de gozar dela com juízo e discrição, apesar dos incendiários, que procuram encaminhá-los para o mal, empregando para isso escritos insidiosos».

Sua ideologia continuava pequeno-burguesa. «Sirvo-me de ideias caseiras, que são o património daquele que é falto de literatura». É um patriota; «o bem da pátria não lhe consente falar nos males

Cabral, Annaes da Imprensa Nacional, Rio de Janeiro, 1881, p. 660, e Damião Peres, Historia de Portugal, Barcelos, 1934, vol. VI, p. 86.

(1) Carta do Compadre de Belém, ob. cit., p. 7.

(2) Ao Redator do Astro da Lusitania dada à luz pelo Compadre de Lisboa, reimpresso no Rio de Janeiro, 1821. Atribuição de A. VAlle CABral, ob. cit., n. ${ }^{0} 670$. 
dela sem comoção de espírito». Interpretando a opinião liberal escrevia que «os nossos desejos são de homens que procuram ser livres, respeitando sempre o Trono, o Altar, o Direito Público, e o das Gentes... Os nossos princípios são de melhorar, e não de destruir. Que a moderação, e a suavidade, glorioso timbre de um governo justo e ilustrado, hão-de acompanhar sempre as medidas empregadas nas operações económicas das reformas, que forem necessárias. E que finalmente a nossa conduta pode servir de exemplo e modelo aos povos do Universo que quiserem regenerar-se, porque em nossa Revolução não separamos ainda, nem as ideias morais das ideias liberais, nem Justiça da Polícia.»

E finalmente sustentava Manuel Fernandes Thomaz a versão liberal, que foi no Brasil adoptada, que «a casa de Bragança reina entre nós, porque nós a chamámos para isso em 1640. O tempo e as circunstâncias havendo-as alterado, nós agora fizemos valer nossos direitos, e só buscamos, que eles sejam respeitados, porque respeitamos sempre, e sempre respeitaremos aqueles, que então concedemos, e a que nos obrigamos» (1).

Negava-se assim a tese conservadora da continuidade desde Ourique, e fazia-se da realeza uma doação popular, tese muita cara aos liberais brasileiros.

Estava Manuel Fernandes Thomaz muito confiante e optimista como todo liberal. "Deixe ao Congresso Nacional o cuidado de estabelecer esses princípios políticos, quando os julgar convenientes; persuada-se, de que em Portugal não se dão hoje nessas matérias novidades em teoria, e que na prática podemos ser os mestres dos outros» (2).

Que se usasse correctamente o conceito do bem público, pois «é uma arma, de que se servem com o mesmo proveito os tiranos da Pátria e os libertadores dela».

Na Carta do Compadre de Lisboa (3), que é um ataque frontal e grosseiro ao Brasil e aos brasileiros, o chefe do liberalismo português volta a defender o governo liberal, que principia a fazer o povo português sentir os benéficos efeitos de uma nova ordem de cousas e a

(1) Carta Segunda, ob. cit., p. 9, nt. 3.

(2) Carta Segunda, ob. cit., p. 10.

(3) Em resposta a outra do Compadre de Belém ou Juizo critico sobre a Opinião Pública, Dirigida pelo Astro da Lusitania, reimpresso no Rio de Janeiro, 1821. Atribuição feita por A. do Valle CABRAl, ob. cit., n. ${ }^{\circ} 661$. 
constituição que se faz e que já se jurou (as bases) e pregava que os meninos fossem desde já imbuídos nos rudimentos de liberdade, igualdade e fraternidade, «que era a trindade dos nossos passados protectores; que se adoptem nas escolas de primeiras letras catecismos, que tenham por base estes luminosos princípios de moral» (1).

Esses princípios eram assim os grandes inspiradores da sociedade liberal, embora Rousseau (2), que estabelecera os princípios fundamentais do governo «natural» fundado sobre a liberdade, a igualdade e a soberania do povo, deixasse de reconhecer a necessidade, para garanti-los, delimitá-los pela organização social. E assim ensinava Manuel Fernandes Thomaz que os liberais princípios não permitiam que se fizesse o que quisesse e que ninguém tivesse direito sobre ninguém (3).

O sistema liberal vinha quebrar os ferros de uma escravidão feudal que datava desde o estabelecimento da monarquia $\left({ }^{4}\right)$.

A literatura panfletária brasileira não era menor no seu fervor liberal. Discutindo as medidas adoptadas pelos mercenários, o autor anónimo liberal defendendo-as invocava logo a igualdade das leis, e declarava que só no tempo dos feudalistas e tiranos aos quais repugnava adoptar o sistema do desinteressado liberalismo se chamaria a reforma de crime e de anarquia (5).

O liberalismo português, como o brasileiro, nasceu cheio de contradiçðes. Uma das contradições mais importantes do liberalismo português foi o de querer a liberdade comercial, a liberdade dos portos, só para eles, excluindo o Brasil, que continuaria sujeito ao monopólio. $O$ Portuguez Constitucional (6) sustentara que tempo feliz era aquele anterior à abertura dos portos, quando Portugal era o armazém único do Brasil.

Luís Gonçalves dos Santos (Rio de Janeiro 1767-Rio de Janeiro 1844), chamado vulgarmente padre Perereca, respondeu ao

(1) Carta do Compadre de Lisboa, ob. cit., p. 9.

(2) O Contrato Social ou principios do direito politico, trad. port., Lisboa, 1821 ; Le Contract Social é de 1762.

(3) Carta do Compadre de Lisboa, pp 9-11.

(4) Carta do Compadre de Lisboa, p. 11.

(5) Resposta à Carta do Senhor Christão que para o ser escuza Conegos $e$ Frades enserida no Conciliador n. ${ }^{\circ} 109$ Por Hum Anonymo, Maranhão, 1822.

(6) N.0 72, Lisboa, 15 de Dezembro de 1820. 
chefe liberal português Manuel Fernandes Thomaz, na parte ofensiva da sua Carta do Compadre de Lisboa, com sua Justa Retribuição dada ao Compadre de Lisboa $\left({ }^{1}\right)$, ponto por ponto, agravo por agravo, sem invocar nenhum princípio liberal, e cuja parte deixamos para o capítulo sobre as actividades hostis portuguesas em conjunto com outros folhetos.

Sua resposta ao português constitucional (2) é demonstração das incongruências do liberalismo português, que é contra o comércio livre brasileiro e pelo fechamento dos portos; acusava os males do colonialismo português e respondia às pretensões coloniais do liberalismo português. O Brasil já não era mais colónia desde sua elevação a Reino em 1815, e assim sustentava que desde então um espírito de nacionalidade e de patriotismo começara a avivar os brasileiros.

O liberalismo português, como vimos, de ideias caseiras, que respeita o trono, o altar, o direito público e das gentes, que quer manter o monopólio comercial e a subjugação colonial, era realmente muito conservador.

No Brasil, a princípio, o liberalismo apresentou-se dividido em duas facções, uma muito moderada, tal como a portuguesa, e outra um pouco mais avançada. Ambas começaram sustentando a união, com a autonomia executiva e legislativa e depois a independência. Essa primeira fase não foi senão um disfarce como viram muitos portugueses, especialmente o general Avilez.

O Príncipe não era liberal, como sustentava Marschall em 1821, senão porque ele recebeu dos membros deste partido algumas ideias que não foram bem digeridas, e que a sua falta de experiência e de instrução não lhe permitiam apreciar no seu justo valor, e tendo sofrido do governo do Rei ele atribuía, de boa fé, a esse governo todo mal que padecia (3). O Príncipe não era nem foi liberal, ele serviu-se dos liberais para atingir seus objectivos, assim como os liberais se serviram dele para alcançar seus fins.

(1) Em desagravo dos brasileiros offendidos por varias asserções, que escreveu na sua carta em Resposta ao Compadre de Belém pelo filho do Compadre do Rio de Janeiro, Rio de Janeiro, 2 edições, 1821 e 1822.

(2) Resposta Analytica a hum artigo do Portuguez Constitucional em Defeza dos Direitos do Reino do Brazil por hum Fluminense, Rio de Janeiro, 1821. A atribuição é de A. do Valle Cabral, Annaes cits., n. ${ }^{\circ} 837$.

(3) «Correspondencia do Barão de Marschall», RIHGB, vol. $77 .^{\circ}, 1 .^{\mathrm{a}}$ p. ${ }^{\text {te }}, \mathrm{p} .200$. 
A ideia da aclamação mostrou bem que os liberais queriam sustentar que o Rei não era por direito divino, mas por escolha popular. Essa tese afirmada desde o começo mostrava bem que se procurava romper a continuidade dinástica e a legitimidade por direito divino. O povo possuindo toda a soberania concordava em dividi-la com o Príncipe. Daí a doutrina que os liberais asseveram publicando na imprensa que o Imperador não tinha antepassados (1). Ele era um rei novo, que começava sua carreira por escolha popular, e que assim como o escolhera poderia ter escolhido a república.

Esta tese que Manuel Fernandes Thomaz defendera, como vimos, era generalizada no liberalismo português. $O$ deputado José Joaquim Ferreira de Moura reafirmou o princípio nas Cortes dizendo que o direito da coroa sempre fora um donativo do povo (2).

Se D. Pedro teria se servido dos liberais e estes dele, o mesmo jogo se deu com José Bonifácio. Cipriano Barata escreveu que ele «serviu-se dos liberais para poder fundar o Império, e depois usando de manha e má fé, deu cabo de todos, para ficar em campo, praticando o mais negro artefacto e horrorosas perfídias, afim de edificar o templo do despotismo" (3).

Se José Bonifácio serviu-se dos liberais, estes dele se serviram, até à separação em outubro de 1822 , quando a independência estava declarada, embora não consolidada. E se Barata não é um anarquista, como não o é João Soares Lisboa, mas liberais radicais, como este, e radicais como o primeiro, eles não constituíam uma súcia, como os chamou $O$ Tamoyo neste artigo.

Houve quase sempre moderação entre as várias correntes que conduziram o Brasil à independência. Todos ficaram juntos, liberais moderados e extremados, conservadores constitucionais, radicais, mas com o tempo se separaram, até que D. Pedro I, em novembro de 1823, se desmascarou, juntando-se aos portugueses sem cor, e aos brasileiros servis e aliados dos portugueses. Aí acabou o liberalismo até 1826, quando reabriu o Parlamento, que ficou muito coagido, até se libertar e preparar a queda de D. Pedro I em 1831, quando o liberalismo ressurgiu.

(1) «Annotações de A.M.V. de Drummond à sua biografia», $A B N$, vol., $13 .^{\circ}$, p. 58.

(2) José da Silva Lisboa, Historia dos Principaes Sucessos Politicos do Imperio do Brasil, Rio de Janeiro, 1827, parte X, p. 105.

(3) $O$ Tamoyo, n. ${ }^{\circ} 13$, sabado, 20 de setembro de 1823 , p. 52. 
As ideias liberais do tempo, escreveu José da Silva Lisboa, consideravam justo e necessário moderar a autoridade suprema não menos para o bem dos povos, que para a segurança dos tronos dando aos súbditos constituição adequada às circunstâncias do país (1).

Não era só José da Silva Lisboa, um conservador, que pensava assim. Pelo Brasil inteiro membros das juntas governativas falavam na «bem entendida liberdade», na «bem entendida independência». Quando em Mato Grosso surgiu a cisão entre Cuiabá e a própria cidade de Mato Grosso, a junta unida escreveu a D. Pedro que «o liberalismo de mãos dadas com a justiça, com que V.M.I., fez unanimizar os espíritos, até então dissidentes, entre as duas cidades desta Província, é hoje objecto de geral satisfação» (2).

Também era bom que no exterior nos vissem assim liberais moderados. Felisberto Caldeira Brant Pontes escrevia de Londres a José Bonifácio dizendo-lhe que era «urgente, urgentíssimo, que não escape uma só palavra, e ainda menos acção, que seja susceptível de sinistra interpretação contra a corrente das ideias liberais. Se nas medidas adoptadas no Rio depois da reunião dos deputados houver alguma, que não seja liberal, e própria de uma monarquia constitucional, ai de nós que sofreremos guerras civis e desgraças por longo tempo» (3).

Quase um ano depois, Brant volta a insistir com José Bonifácio, para que se construa uma imagem liberal do Brasil. «Quando na Europa houver certeza de que no Império do Brasil há liberdade de consciência, e segurança de propriedade mui considerável será a imigração, e mui rápido o engrandecimento do Império» (4).

De modo que pouco a pouco José Bonifácio, que fora um conservador sensível às reformas, caminhou para um liberalismo constitucional, ou melhor ainda, para um monarquismo constitucional, ao contrário de seus adversários, que seguiam rotas radicais ou extremadas. Esse liberalismo moderado, que preservasse a monarquia e a constituição, dominou José Bonifácio e Hipólito da Costa. Quando José Bonifácio quis avançar enfrentando problemas económicos e sociais, a escravidão, os índios, a terra, aí encontrou a formidável oposição dos grandes proprietários brasileiros e portugueses, e viu

(1) Historia dos Principais Sucessos Politicos, parte X.

(2) As Juntas Governativas e a Independência, Rio de Janeiro, 1973, 3 vols.

(3) Londres, 17-25 de junho de 1822, ADI, I, p. 175.

(4) Londres, 1 de junho de 1823, ADI, I, p. 264. 
aliarem-se contra ele os liberais de todas os matizes, e os radicais e republicanos, estes porque queriam sua queda.

Esse liberalismo inconformado, conspiratório, militarista, preso às fórmulas legais, insensível aos problemas sociais e económicos, à injustiça social, disposto a alcançar o poder por qualquer meio, nasceu na corrente ideológica da independência.

A tentativa falhada de afastar José Bonifácio em outubro de 1822 é a primeira da série de golpes de Estado civis e militares com que os liberais marcaram a história brasileira.

Os liberais ao correr do tempo construíram uma concepção histórica da independência. Timandro, o liberal depois convertido ao conservadorismo, Francisco Sales Torres Homem, no seu panfleto político extremamente violento contra o Imperador, logo após o esmagamento da revolução praieira, escreveu que a crise de então não era senão um prolongamento da crise da independência. Foi no antagonismo entre a soberania nacional e a prerrogativa real que Timandro procurou as raízes dos males presentes. A facção antinacional que se apoderara do poder por ambição de proveito, de fortuna, de rivalidade, aproveitando-se do sangue derramado, é culpada pela crise «que há vinte e cinco anos começou, enlutando as últimas cenas da nossa incompleta independência».

"A revolução da independência» continua Timandro, «que devolveu-nos à posse de nós mesmos, firmava como dogma fundamental da nova ordem social o grande princípio da soberania popular. No interior como no exterior, esse princípio, que é a pedra angular dos estados livres, tornava-nos os árbitros únicos, supremos, e absolutos de nossos próprios destinos. Só do povo; só de suas luzes, e espontânea deliberação pendia a escolha da organização política, que desde então devia regê-lo; só a ele, e a mais ninguém cabia traçar e erguer o novo edifício, em que havia de abrigar-se a nascente nacionalidade. Todos os laços, que prendiam-nos ao passado, estavam mortos; tínhamos recebido uma segunda vida, uma segunda natureza, que anulava e excluía as pretençōes da realeza da conquista».

«Em virtude daquele direito, preferiu a nação a monarquia do mesmo modo que poderia preferir a república de Franklin e de Washington; aclamou por seu rei o primogénito da casa de Bragança como aclamaria o filho do Grão-Turco, se fora seu gosto. Esse rei era simples feitura de nossas mãos; nenhum título antigo e preexistente o assistia, porque tudo era novo, tudo datava de ontem nesta situação; 
o solo estava varrido e limpo; seu único título de legitimidade vinha da eleição nacional, título aliás mais belo e honroso do que o acaso cego do nascimento; seu trono, contemporâneo de nossa liberdade, repousava sobre a mesma base que ela - a revolução».

Depois que se fez o Rei, começou a se fazer o pacto primitivo da sociedade. "O poder constituinte é parte essencial da soberania da nação, a qual delega o seu exercicio, sem nunca abdicá-lo».

«Mas ainda corria em meio a construção da obra constitucional, quando de improviso é profanado e dissolvido com mão armada o congresso, a quem o país cometera essa sublime tarefa, e são atirados ao desterro os seus mais conspícuos e beneméritos representantes, os fundadores ilustres da independência da pátria». "Houve a usurpação da soberania popular por aquilo que a Corte designa com diversos nomes - soberania real, direito divino, prerrogativa, legitimidade, poder hereditário. A nova realeza saída da lavra da nação, ostenta-se superior a ela, ataca-a, e a absorve em si» (1).

Alguns anos antes, em 1841, em sessão da Câmara dos Deputados, num debate entre o conservador Honório Hermeto Carneiro Leão, depois Marquez de Paraná, e Theofilo Ottoni sobre a legitimidade do Imperador, que para o primeiro não vinha só da constituição, e que sustentara que o governo era sempre legítimo quando à sua frente estava o Imperador, o segundo deu a sua versão liberal da história da independência. Ele a começa em 1821, quando D. João VI voltara a Portugal e estava governando os três Reinos, sendo o seu governo o único legítimo. Entretanto, o Brasil, depois de ter nomeado deputados às cortes gerais, reconheceu que o governo de Portugal não correspondia às suas intençð̃es e se rebelou, e da rebelião saiu vitorioso. A quem se fazia a guerra? perguntou Ottoni. "Ao governo legítimo, a cuja testa estava o sr. D. João VI». A falta de fé com que o governo português nos tratava violou o pacto fundamental da monarquia, e por isso correram às armas.

Carneiro Leão dissera que a legitimidade do Imperador não vinha só da constituição, mas da unânime aclamação dos povos. Ottoni respondeu-lhe que quando a constituição falava em unânime aclamação dos povos não mencionava um fato, mas dava um título. «E nem

(1) O Libello do Povo por Timandro, Rio de Janeiro, 1849; 4. ${ }^{\mathrm{a}}$ ed., R. Magalhães Jr., Três Panfletários do Segundo Reinado, São Paulo, 1956, pp. 62-64. 
de outra sorte se podia considerar esse artigo da constituição porque o Sr. D. Pedro I não foi aclamado unanimemente. Sabe-se que houve dissidências, tanto de brasileiros, que pretendiam outra forma de governo, como do partido português que pretendia recolonizar-nos. Por consequência, não foi aclamado unanimemente, e não é da aclamação que vem o título, mas da constituição».

"O fim da revolução era a liberdade». E depois de rememorar os factos principais, e de sustentar que antes da aclamação do imperador existia a convocação da assembleia geral constituinte, Ottoni declarava que Carneiro Leão podia recorrer às actas das câmaras municipais onde o imperador fora aclamado, e achará condições muito expressas sobre o poder real e o povo. "A nação brasileira reconhecendo o seu poder, a força, e o direito, que tinha recobrado tornando-se independente de Portugal, disse ao príncipe, como os aragoneses de outr'ora: Nós, que somos tanto quanto vós, e que podemos mais que vós, nós vos fazemos imperador constitucional, com a condição de que respeitareis as instituições que a convenção ou assembleia constituinte, que já se acha convocada, houver de instituir». O Imperador jurou, acrescentou Ottoni, e se obrigou a respeitar a constituição (1).

Não podia haver maior confusão doutrinária; o conservador afirmando a legitimidade do imperador pela aclamação popular e o liberal negando essa doutrina. Ambos intelectualmente eram bem inferiores a Sales Torres Homem, o Timandro, liberal consciente, conservador por interesse. De Honório Hermeto disse João Loureiro, um português contra-revolucionário e tradicionalista que viveu nesta época, que tinha «boa moral, bom carácter, presunção, e pouco saber» (2), e de Theofilo Ottoni, muito inteligente, mas leviano, que ele preparava as justificativas para a revolta liberal de 1842 em São Paulo e Minas Gerais.

Concluindo, o liberalismo moderado e contido, quase diríamos anti-democrático no princípio, e indiferente à democracia a longo prazo, nasceu marcado pela sua convivência com a escravidão. No

(1) A Circular de Theophilo Ottoni, 1. a ed., Rio de Janeiro, 1860, reprodução dirigida por Basílio de Magalhães, Rio de Janeiro, 1910, pp. 161-173. Os discursos de Carneiro Leão e Theophilo Ottoni se encontram nos $A C D$, nas sessões de 9 e 12 de julho de 1841, t. $2 .^{\circ}$, Rio de Janeiro, 1883.

(2) «Cartas de João Loureiro escriptas do Rio de Janeiro ao Cons. M. J. Maria da Costa Sá de 1828 a 1842», RIHGB, vol. $76 .^{\circ}$, parte 2, p. 403. 
governo e na constituinte não foi a ala liberal que combateu a escravidão; o plano para aboli-la gradualmente veio de José Bonifácio. Esta falta de consciencia social qualificou o liberalismo brasileiro por muito tempo, e são excepcionais suas figuras que saem deste padrão comum até à época moderna. Foi um liberalismo o menos liberal possível, entendido que isso significava que as liberdades e garantias que constituem a essência do liberalismo, atingissem o grupo social mais selecionado possível e não se estendessem às camadas mais populares. As discriminações não foram só sociais, foram também políticas, isto é, havia dissidentes políticos, seus iguais, que mereciam seu apoio, e havia revoltados, desiguais, que não tinham direito ao seu patrocínio.

A contenção do liberalismo deste começo nacional e que se prolongou por toda a nossa história não se casa não digo só com o povo, mas com a maioria manifesta, e não absoluta. Como tenho escrito e repetido sempre, o problema político brasileiro mais importante foi sempre o direito das maiorias, e não das minorias, que são as donas do poder. Muitas vezes as pequenezas políticas e sociais, e a indignação moral da classe média, davam ao liberalismo o espírito acanhado que se apresentou ao longo da história.

Mas essas críticas revelam sobretudo a gama imensa da opinião liberal no país. O lado positivo é a luta na imprensa e no parlamento contra todos os abusos do Poder, as arbitrariedades policiais, as comissões militares de julgamento de presos políticos, e a favor das liberdades e garantias individuais pelas quais muitos dos seus líderes lutaram desde o começo, e a consciência de que o país tinha um destino democrático ${ }^{(1)}$.

José HONÓRIO RODRIGUES

(1) Vide José Honório Rodrigues, O Parlamento e a Evolução Nacional, Brasilia, Senado Federal, 1972. 